\title{
Role of CT Nose Paranasal Sinuses and Nasal Endoscopy for Decision Making in a Case of Deviated Nasal Septum
}

\author{
Sayan Hazra, ${ }^{1}$ Ankit Choudhary, ${ }^{1}$ Swapan Kumar Ghosh, ${ }^{1}$ Subhradev Biswas, ${ }^{1}$ Kaustuv Das Biswas ${ }^{1}$
}

\section{Introduction}

\section{$\underline{\text { ABSTRACT }}$}

Deviated nasal septum (DNS) can be asymptomatic in an individual or may cause nasal obstruction. The condition is generally diagnosed clinically and based on clinical diagnosis it is managed Surgically by large without much heed to diagnostic procedure. Thus, often underlying other causes of Obstruction is missed. Thus, it becomes essential to evaluate every patient presenting with history of Nasal obstruction and clinically Deviated septum, with aid of Nasal Endoscopy and CT scan Nose Paranasal Sinuses (PNS) to rule out/diagnose other coexisting conditions.

\section{Materials and Methods}

100 patients who presented with nasal obstruction and clinically diagnosed to have Deviated Nasal Septum were then subjected to Nasal Endoscopy and CT scan Nose and PNS and findings were noted for analysis.

\section{$\underline{\text { Results }}$}

Of these 100 patients, 48 patients were found to have coexisting pathological conditions/anatomical variants. Various anatomical and pathological Conditions were found to coexist together. Inferior turbinate hypertrophy in $34 \%$ is the most common pathological condition found to be associated with DNS followed by of sinusitis in 25\% patients apart from polyp, concha bullosa and paradoxical middle turbinate.

\section{Discussion}

Studies done so far shows there is a definite link of deviated nasal septum to various anatomical and pathological conditions of the nose. CT Scan Nose PNS and Nasal Endoscopy plays a vital role in diagnosing such anomalies.

\section{Conclusion}

Most of the patients, presenting with nasal obstruction and having Deviated Nasal Septum, undergo management without proper analysis and returns with recurrence of symptoms which could be analyzed properly if Nasal endoscopy and CT scan is employed during diagnosis of the condition, reducing risk of treatment failure.

$\underline{\text { Kevwords }}$

Nasal Septum; Nose Deformities; Nasal Obstruction; Tomography, X-Ray Computed

$\mathrm{T}$ he nasal septum comprising of bony and cartilaginous parts divides the nasal cavity into right and left halves both anatomically and physiologically. It is an accepted fact that some amount of deviation of nasal septum is common and having a perfectly straight septum is a rarity. Deviated nasal septum (DNS) can be asymptomatic or may cause nasal obstruction. The condition is generally diagnosed clinically and based on clinical diagnosis it is managed surgically by and large without much heed to diagnostic procedure. Thus, often other underlying causes of obstruction are missed. Along with nasal obstruction symptoms of rhinosinusitis like nasal discharge, headache, epistaxis, disturbance of smell, etc. may also be there. Various other anatomical variants and pathological conditions such as concha bullosa, paradoxical middle turbinate, inferior turbinate hypertrophy, polyp, sinusitis may coexist along with Deviated Nasal Septum. Even in absence of significant deviation of septum these conditions often present with similar clinical picture to

1 - Department of ENT, IPGMER \& SSKM Hospital, Kolkata

\section{Corresponding author:}

Dr Ankit Choudhary

email: dr.ankitchoudhary@gmail.com 
Table I: Distribution of patients as per type of Deviation

\begin{tabular}{|c|c|c|}
\hline TYPE OF DEVIATION & NO OF PATIENTS & PERCENTAGE \\
\hline C- shaped & 44 & 44 \\
\hline S- shaped & 12 & 12 \\
\hline Caudal dislocation & 24 & 24 \\
\hline Spur & 16 & 16 \\
\hline Thickened Septum & 4 & 4 \\
\hline
\end{tabular}

that of DNS. Thus, it becomes essential to evaluate every patient presenting with history of nasal obstruction and clinically deviated septum, with aid of Nasal Endoscopy and CT scan of Nose and PNS to rule out/diagnose other coexisting conditions. It not only helps us in diagnosis but also aids in proper planning of management of the said patient.

\section{Materials and Methods}

A prospective study was done at a tertiary care hospital comprising of 100 patients, who presented with nasal obstruction and were clinically diagnosed to have Deviated Nasal Septum. The study was done in a span of 18 months. Thorough history was taken and detailed clinical examination was done in all the cases. Patients above 5 years of age, who were willing to take part in the study through written informed consent, were included in the study. Patients having Deviated Nasal Septum but not complaining of nasal obstruction or patients having Nasal Obstruction but no deviation of Nasal Septum, patients with nasopharyngeal mass as well as those with past history of any nasal surgery were excluded.

All the patients in the study population were subjected to Nasal Endoscopy and CT scan of Nose and PNS and findings were noted for analysis.

\section{Nasal Endoscopy}

Diagnostic Nasal endoscopy, because of brighter illumination, magnification and angled views provide examination of all the clefts and crevices of nose. It is done under topical anesthesia with $4 \%$ Lignocaine and a
Vasoconstrictor viz., Oxymetazoline soaked nasal packs. Nasal packs are removed and then Nasal endoscopy is performed by three passes using $0^{\circ}$ Nasal Endoscope.

In the First Pass- Endoscope is passed along the floor of Nasal Cavity; in Second Pass- Endoscope is passed medial to the Middle Turbinate and in the Third PassEndoscope is passed lateral to the Middle Turbinate.

\section{CT Scan Nose PNS}

CT Scan Nose PNS done for the study employed 1 $\mathrm{mm}$ cuts in Axial Sections with Coronal and Sagittal Reconstruction.

\section{Results}

Patients were assessed for demography, type and side of deviation, association of different types of deviation with various clinical features. Various pathological conditions/anatomical variants which would have contributed to nasal obstruction, diagnosed by CT Scan and Nasal Endoscopy were noted. These findings would have been otherwise missed resulting in incomplete management. Sixty eight percent $(68 \%)$ of patients presenting with nasal obstruction with Deviated Nasal Septum were male with majority of patients in the age group of $16-25$ years (51\%). Majority of patients had right sided deviation in the study (55\%). C-shaped deviation was most commonly seen in the study population (44\%) (Table I).

Of 100 patients 48 patients were found to have coexisting Pathological / Anatomical variants. Various anatomical and pathological conditions were found 
Table II: Incidence of another Pathology/ Anatomical Variant as diagnosed by CT scan/ Nasal Endoscopy

\begin{tabular}{|c|c|c|}
\hline $\begin{array}{c}\text { PATHOLOGY/ ANATOMICAL } \\
\text { VARIANT }\end{array}$ & $\begin{array}{c}\text { NO OF CO-EXISTING } \\
\text { PATHOLOGY/ ANATOMICAL } \\
\text { VARIANT }\end{array}$ & PERCENTAGE \\
\hline Polyp & 10 & 10 \\
\hline Sinusitis & 25 & 25 \\
\hline Concha Bullosa & 12 & 5 \\
\hline Paradoxical Middle Turbinate & 5 & 34 \\
\hline
\end{tabular}

to coexist. Inferior turbinate hypertrophy is the most common pathological condition found to be associated with DNS (in 34\%) followed by sinusitis in $25 \%$ patients (Table II). Inferior Turbinate hypertrophy, though can be diagnosed clinically, the exact nature i.e., soft tissue hypertrophy or bony hypertrophy cannot be differentiated without CT scan. Many of those patients had coexisting Concha Bullosa or Paradoxical Middle Turbinate or Inferior Turbinate hypertrophy.

Inferior turbinate hypertrophy was more commonly found to be associated with $\mathrm{C}$ shaped deviation followed by sinusitis (Table III). Inferior turbinate hypertrophy was also found to be associated with septal spur with higher incidences. Concha Bullosa was seen to be more common in patients with $\mathrm{C}$ shaped deviation.
Thus, a good $48 \%$ of cases which would have otherwise been incompletely managed because of incomplete diagnosis could be diagnosed completely with CT Scan and Nasal Endoscopy. (Table IV)

\section{Discussion}

Our study is in concordance to various literature and studies. $25 \%$ of patients of DNS with nasal obstruction in our study were found to have CT scan and nasal endoscopic features suggestive of sinusitis while $34 \%$ of patients had inferior turbinate hypertrophy. Concha bullosa was seen to coexist in $12 \%$ of patients. The results are similar to the studies conducted by Elahi \& Frenkiel, ${ }^{1}$ Smith et $\mathrm{al}^{2}$ and Cotter et.al. ${ }^{3}$ All these

Table III: Coexistence of different types of DNS with another pathology / anatomical Variant

\begin{tabular}{|c|c|c|c|c|c|c|}
\hline \multirow{2}{*}{$\begin{array}{l}\text { TYPE OF } \\
\text { DEVIATION }\end{array}$} & \multirow{2}{*}{$\begin{array}{c}\text { NO OF } \\
\text { PATIENTS }\end{array}$} & \multicolumn{5}{|c|}{ OTHER ASSOCIATED FINDINGS } \\
\hline & & POLYP & SINUSITIS & $\begin{array}{c}\text { CONCHA } \\
\text { BULLOSA }\end{array}$ & $\begin{array}{l}\text { PARADOXICAL } \\
\text { MIDDLE } \\
\text { TURBINATE }\end{array}$ & $\begin{array}{c}\text { INFERIOR } \\
\text { TURBINATE }\end{array}$ \\
\hline C-shaped & 44 & 5 & 14 & 8 & 2 & 16 \\
\hline S- shaped & 12 & 3 & 3 & 2 & 2 & 3 \\
\hline $\begin{array}{c}\text { Caudal } \\
\text { dislocation }\end{array}$ & 24 & - & 2 & 1 & - & 5 \\
\hline Spur & 16 & 2 & 6 & 1 & 1 & 9 \\
\hline $\begin{array}{c}\text { Thickened } \\
\text { Septum }\end{array}$ & 4 & - & - & - & - & 1 \\
\hline
\end{tabular}


Table IV. Clinical Diagnosis Versus CT Scan/ Nasal Endoscopy

\begin{tabular}{|c|c|c|}
\hline \multirow{2}{*}{} & \multicolumn{2}{|c|}{ CT SCAN / NASAL ENDOSCOPY FINDING } \\
\cline { 2 - 3 } & DNS ONLY & DNS WITH OTHER PATHOLOGY \\
\hline Clinically DNS & 52 & 48 \\
\hline
\end{tabular}

studies showed a high incidence of sinusitis in patients of deviated septum. Matschke \& Fliebach ${ }^{4}$ and Danese et $\mathrm{al}^{5}$ also found an association between septal deviation and sinus disease as assessed by CT scan in their respective studies. Rehman et al, ${ }^{6}$ in their study, found $23.7 \%$ cases having concha bullosa and $7 \%$ patients with paradoxical middle turbinate additionally on CT scan. Inferior turbinate hypertrophy was present in $46 \%$ of those cases. These results were further substantiated by studies conducted by Orhan et al, ${ }^{7}$ Aktas et al. ${ }^{8}$

Our study also revealed that inferior turbinate hypertrophy was more commonly associated with $\mathrm{C}$ shaped deviation followed by sinusitis. They were also found to exist in large number of cases of septal spur. Concha bullosa was seen most commonly in patients with $\mathrm{C}$ shaped deviation. In a study done by Moorthy et al, ${ }^{9} \mathrm{C}$ - shaped deviation was associated with pansinusitis in $50 \%$ of patients, S-shaped deviation was associated with pansinusitis in $83.3 \%$, spur was associated with pansinusitis in $30 \%$ of patients. Danese et $\mathrm{al}^{5}$ and Calhoun et $\mathrm{al}^{10}$ also found in their study that septal deviation was associated with ostiomeatal complex disease.

Headache was associated in cases of sinusitis which links it with sinusitis along with Deviated Nasal Septum. It was also seen that nasal discharge, headache and hyposmia are not only because of the Deviated Nasal Septum itself but is also linked with various other pathological/ anatomical variants which coexisted in many of the symptomatic patients of Deviated Nasal Septum.

CT scan needs to be supplemented with Nasal Endoscopy in all the cases of Deviated Nasal Septum as all these pathological / anatomical variations are not identified by CT scan alone. Again, in a symptomatic patient of Deviated Nasal Septum with other nasal pathology or anatomical variant, some component of obstruction may be because of the anatomical variant/ pathology which needs to be corrected medically/ surgically before or along with correction of Deviated Nasal Septum to get optimal results. Like a diagnosed case of sinusitis should be managed medically before undergoing any surgery, in a case of large concha bullosa with Deviated Nasal Septum with nasal obstruction, concha bullosa needs to be reduced surgically.

\section{Conclusion}

Most of the patients, presenting with nasal obstruction and having Deviated Nasal Septum, undergo management without proper analysis and return with recurrence of symptoms which could have been analyzed properly if nasal endoscopy and CT scan were employed during diagnosis of the condition, reducing risk of treatment failure. Thus, in patients of deviated nasal septum presenting with nasal obstruction a thorough history and clinical examination must be followed by a nasal endoscopy and CT scan to look for other anatomical variants and associated pathology as various symptoms may be contributed by those pathologies and not by the deviated septum only.

\section{References}

1. M. M. Elahi MM, Frenkiel S. Septal Deviation and Chronic Sinus Disease. Am J Rhinol. 2000; 14(3):175-9. doi:10.2500/105065800782102735

2. Smith KD, Edwards PC, Saini TS. The prevalence of concha bullosa and nasal septal deviation and their relationship to maxillary sinusitis by volumetric tomography. Int J Dent. 2010. pii: 404982. Epub 2010 Aug 24

3. C. S. Cotter, S. Stringer, K. R. Rust and A. Mancuso. The Role of Computed Tomography Scans in Evaluating Sinus Disease in Pediatric Patients. Int J Pediatric Otorhinolaryngol. 1999; 50(1):63-8. doi:10.1016/S0165-5876(99)00204-9

4. Matschke R, Fliebach A. Septum Deviation and Concomitant Sinusitis. HNO 1985; 33(12):541-4

5. Danese M, Duvoisin B, Agrifolio A, Cherpillod J, Krayenbulh 
M. Influence of naso-sinusal anatomic variants on recurrent, persistent or chronic sinusitis, X-ray computed tomographic evaluation in 112 patients. J Radiologie, 1997; 78(9):651-7

6. Rehman, A., Hamid, S., Ahmad, M. and Rashid, A. (2012) A Prospective Study of Nasal Septal Deformities in Kashmiri Population Attending a Tertiary Care Hospital. Int J Otolaryngol Head Neck Surg. 2012; 1:77-84. doi: 10.4236/ ijohns.2012.13016

7. Orhan I, Aydın S, Ormeci T, Yılmaz FA. Radiological analysis of inferior turbinate in patients with deviated nasal septum by using computed tomography. Am J Rhinol Allergy 2014; 28(1):e68-72. doi: 10.2500/ajra.2014.28.4007
8. Aktas D, Kalcioglu MT, Kutlu R, Ozturan O, Oncel S. The relationship between the concha bullosa, nasal septal deviation and sinusitis. Rhinology 2003; 41(2):103-6

9. Moorthy PNS, Kolloju S, Madhira S, Jowkar AB. Clinical Study on Deviated Nasal Septum and its Associated Pathology. International Journal of Otolaryngology and Head \& Neck Surgery 2014; 3:75-81. http://dx.doi.org/10.4236/ ijohns.2014.32016

10. Calhoun KH, Waggenspack GA, Simpson CB, Hokanson JA, Bailey BJ. CT evaluation of the paranasal sinuses in symptomatic and asymptomatic populations. Otolaryngol Head Neck Surg. 1991;104(4):480-3. 